\title{
Preface to the special section on high-temperature capillarity
}

\author{
Boris Straumal $^{1,2} \cdot$ Brigitte Baretzky $^{2}$
}

Received: 30 November 2015/Accepted: 30 November 2015/Published online: 21 December 2015

(C) Springer Science+Business Media New York 2015

This special section contains a selection of papers resulting from presentations made during the international conference, HTC-2015. The 8th High Temperature Capillarity Conference (HTC-2015) took place in Bad-Herrenalb, Germany from 17 to 21 May 2015. HTC-2015 brought together about 100 participants who shared new developments and experiences in the continuously advancing field of high-temperature capillarity. HTC-2015 followed the High Temperature Capillarity conferences held in Eilat, Israel (2012) [1]; Athens, Greece (2009) [2]; Alicante, Spain (2007); Sanremo, Italy (2004); Kurashiki, Japan (2000); Krakow, Poland (1997) and Smolenice, Slovakia (1994). Information about HTC conferences can be found at http://www.htcconference.org/. This conference is held every 3 years and serves as a unique venue for specialists and researchers in different areas of materials science as well as joining technology (welding, brazing, sintering) to discuss and exchange their ideas with each other.

The following topics were selected for the sessions of HTC-2015 Conference

- Capillarity induced microstructural evolution in metals, glasses and ceramics

- Surfaces of liquid metals, glasses and ceramics; surface energy and adsorption

Boris Straumal

straumal@issp.ac.ru; straumal@mf.mpg.de

Brigitte Baretzky

Brigitte.Baretzky@kit.edu

1 Institute of Solid State Physics, Russian Academy of Sciences, Ac. Ossipyan str. 2, Chernogolovka, Russia 142432

2 Institute of Nanotechnology, Karlsruhe Institute of Technology (KIT), Hermann-von-Helmholtz-Platz 1, 76344 Eggenstein-Leopoldshafen, Germany
- Metal-metal, metal-ceramic, metal-glass and ceramic interfaces: wettability, adhesion, interfacial reactions, segregation, grain boundary, wetting and intergranular films

- Capillarity in microgravity

- Marangoni phenomena

- Corrosion and embrittlement by liquid metals

- Advances in measurement techniques

- Modelling and simulation

- Materials processing: crystal growth, heterogeneous nucleation, fundamentals of vapor phase deposition

- Processing of composite materials

- Joining of metals and ceramics.

The phenomena of high-temperature capillarity are especially important for joining. In turn, joining is a key technology for the fabrication of multi-phase and multicomponent components and assemblies for automotive, aerospace, building, energy, electronics and other industrial sectors. Nearly all of our daily products contain joints between different materials. Driven by their increasing performance requirements, which cannot be fulfilled by a single material or component, the importance of the joining technologies is still growing. The possibility of joining advanced materials with ultrafine or nano-engineered structure, as well as the broad variety of materials and miniaturized components integrated in joint assemblies, represents additional technological challenges. These challenges can only be met by gaining a comprehensive fundamental understanding of the interplay between the various phenomena that govern the joining process, such as (inter-)diffusion, wetting, melting and phase transformations.

The conference has been organized jointly by the Karlsruhe Institute of Technology (KIT), Institute of 


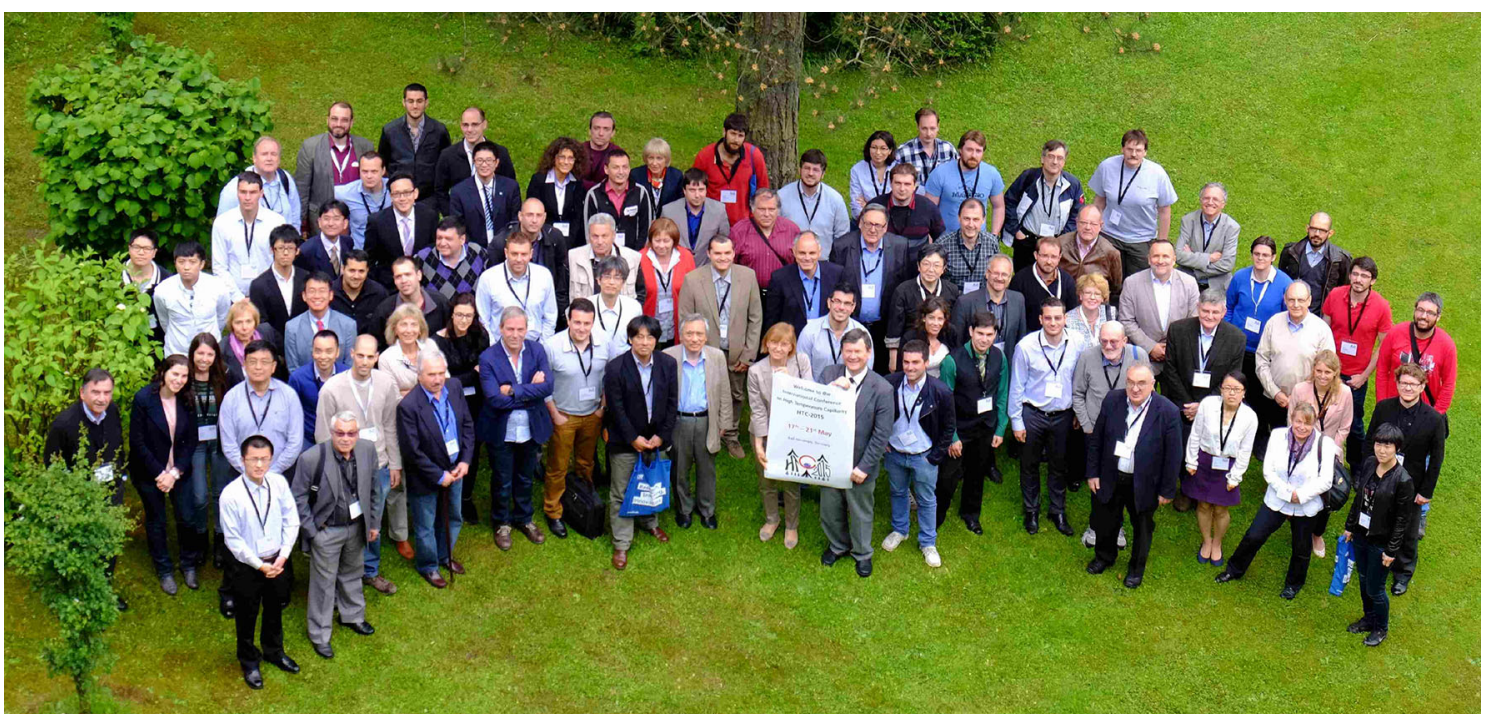

Nanotechnology, Eggenstein-Leopoldshafen, Germany and the Institute of Solid State Physics, Russian Academy of Sciences, Chernogolovka, Russia. Bad-Herrenalb is a beautiful place in the Black Forest close to Karlsruhe and Baden-Baden, Germany. HTC-2015 took place in the conference hotel "Haus der Kirche" which possesses excellent facilities and rooms for the organization of conferences, workshops and seminars for up to 130 participants. During the conference, 8 invited and 35 oral talks took place in addition to 29 poster presentations. The 16 papers collected in this issue were reviewed according to the usual strict reviewing policies of the journal, and only those meeting the quality required for regular papers were accepted for publication.

We hope this special section contributes a lot to further enhance research in the field of high-temperature capillarity. We acknowledge the great efforts of the HTC2015 organizing committee members, the international advisory board members and the members of JMS team, particularly Professor Alberto Passerone, Professor Mark Aindow and Professor C. Barry Carter, for their help in editing this JMS special section.

\section{References}

1. Kaplan WD (2012) Preface to the HTC 2012 special issue. J Mater Sci 47:8245-8246. doi:10.1007/s10853-012-6849-5

2. Eustathopoulos N, Kaptay G, Nikolopoulos P, Passerone A (2010) Guest editors' editorial: HTC-2009. J Mater Sci 45:1977-1978. doi:10.1007/s10853-010-4253-6 